Daimon. Revista Internacional de Filosofía, $n^{\circ} 78,2019$, pp. 13-15

ISSN: 1130-0507 (papel) y 1989-4651 (electrónico)

http://dx.doi.org/10.6018/daimon/400941

\title{
El vigor de la razón dialógica
}

\author{
The vigor of dialogic reason
}

ADELA CORTINA*

El 15 de mayo murió en su casa de Niedernhausen a los 95 años Karl-Otto Apel, uno de los mejores filósofos de los siglos XX y XXI. Nacido el 15 de marzo de 1922 en Düsseldorf, su biografía intelectual viene jalonada por estudios de historia, germanística y filosofía, con Erich Rothacker, en la Universidad de Bonn, y más tarde, por la elaboración de una propuesta filosófica, que tiene por hilo conductor la atención al lenguaje como el lugar desde el que los seres humanos hacen ciencia y ética, desde el que son posibles la comprensión y la acción.

Su trabajo de habilitación (1961) versa sobre la idea del lenguaje en la tradición del humanismo de Dante a Vico, y en los años de profesor en Kiel, Saarbrücken y Frankfurt, donde permaneció desde 1972 hasta convertirse en profesor emérito en 1990, se adentró en los caminos de la hermenéutica de Dilthey, Heidegger y Gadamer, en el pragmatismo de Peirce, en la filosofía del lenguaje de Humboldt, Wittgenstein, Searle o Austin.

En diálogo con ellos, y muy especialmente con Kant, elaboró la propuesta que apareció en La transformación de la filosofía (1973), a la que siguieron Diskurs und Verantwortung (1988), en que aplica la ética del discurso a distintos ámbitos, un volumen de Auseinandersetzungen (1998), de cuya parte final -las discusiones con Habermas- hay versión española de Norberto Smilg en Comares, Paradigmen der ersten Philosophie (2011) y recientemente Transzendentale Reflexion und Geschichte (2017).

Estos son algunos datos sobre el legado de un pensador que unía su vigorosa aportación filosófica a una cordial personalidad. Casado con Judith, una mujer extraordinaria, tenía tres hijas, a las que adoraba, disfrutaba compartiendo el tiempo con sus amigos, se enfurecía cuando perdía la selección alemana y le gustaba el vino tinto, pero sobre todo podía pasar horas enteras discutiendo apasionadamente de filosofía, porque creía en su importancia para la vida de las personas y de los pueblos. Como su colega y gran amigo Jürgen Habermas, experimentaba la necesidad de evitar recaer en situaciones como la del nacionalsocialismo, que surgió, entre otras cosas, del rechazo al pensamiento, a la argumentación y la crítica. Se

Contribución invitada por el Editor del monográfico. Publicada originalmente en el diario El País, sección Babelia, el 26 de mayo de 2017: https:/elpais.com/cultura/2017/05/23/babelia/1495553808_193154.html Catedrática Ética y Filosofía Política de la Universidad de Valencia. Correo electrónico: Adela.Cortina@uv.es 
decía en aquel tiempo - contaba Apel- que Hitler había sabido conectar con el "sano sentir" del pueblo, y por eso se desaconsejaba argumentar y dar razón. Bastaba con obedecer al Führer, al caudillo, que encarnaba la voz del pueblo.

La consecuencia -el Holocausto- no pudo ser más deplorable, por eso la filosofía tenía que recuperar su fuerza crítica, su responsabilidad de dar razón en el ámbito teórico y en el práctico, su capacidad de fundamentar frente al totalitarismo y al dogmatismo de lo irracional. Tenía que tomar la iniciativa para impedir ese expectante dejar ser a cualquier caudillo que conecte con la dimensión irracional del pueblo. Para impedir que Auschwitz se repita.

De ahí que Apel se haya esforzado por recordar, junto a Habermas, que los seres humanos se hacen desde el diálogo, y no desde el monólogo impositivo, que es preciso argumentar, y no sólo sentir, para descubrir cooperativamente qué es lo más verdadero y lo más justo.

En esta línea irían su antropología del conocimiento, su hermenéutica y pragmática trascendentales, la semiótica como filosofía primera, la teoría de los tipos de racionalidad, la teoría consensual de la verdad y la ética del discurso, en su doble nivel de fundamentación y aplicación a distintos problemas contemporáneos.

Para algunos de los que en los setenta del siglo pasado empezamos a oficiar de filósofos estas propuestas fueron un soplo de aire fresco. Presentaban una alternativa vigorosa al positivismo, empeñado en negar la racionalidad del mundo moral y político, por no ser un mundo de hechos comprobables; pero también al individualismo neoliberal, basado en el solipsismo metódico, incapaz de descubrir el vínculo de intersubjetividad que une a los seres humanos; al relativismo escéptico en el mundo moral, que ningún ser humano es capaz de vivir en serio; a la tecnocracia y el mercantilismo de la razón instrumental. Daban cuenta de la pretensión de universalidad que anida en el corazón de quien ante situaciones indignantes las tacha de injustas, y está dispuesto a dar razón de su crítica. Porque presupone pragmáticamente, lo quiera o no, que en una situación ideal de argumentación sería posible encontrar la respuesta más adecuada.

La propuesta de Apel ha sido y es decisiva en el hacer de estudiosos de todo el mundo, especialmente de Iberoamérica y Europa. Baste recordar a jóvenes filósofos como Kettner, Hösle o Forst, el diálogo cordial con Javier Muguerza, los trabajos de tantos filósofos españoles, entre ellos, del grupo de Valencia y Castellón, al que pertenezco. Como también la dedicatoria de Habermas al comienzo de Conciencia moral y acción comunicativa: "de entre los filósofos vivos ninguno ha influido más en mi pensamiento que Karl-Otto Apel".

Contar con la persona, la filosofía y la amistad cordial de Apel ha sido un gran regalo por el que no cabe sino dar las gracias. 


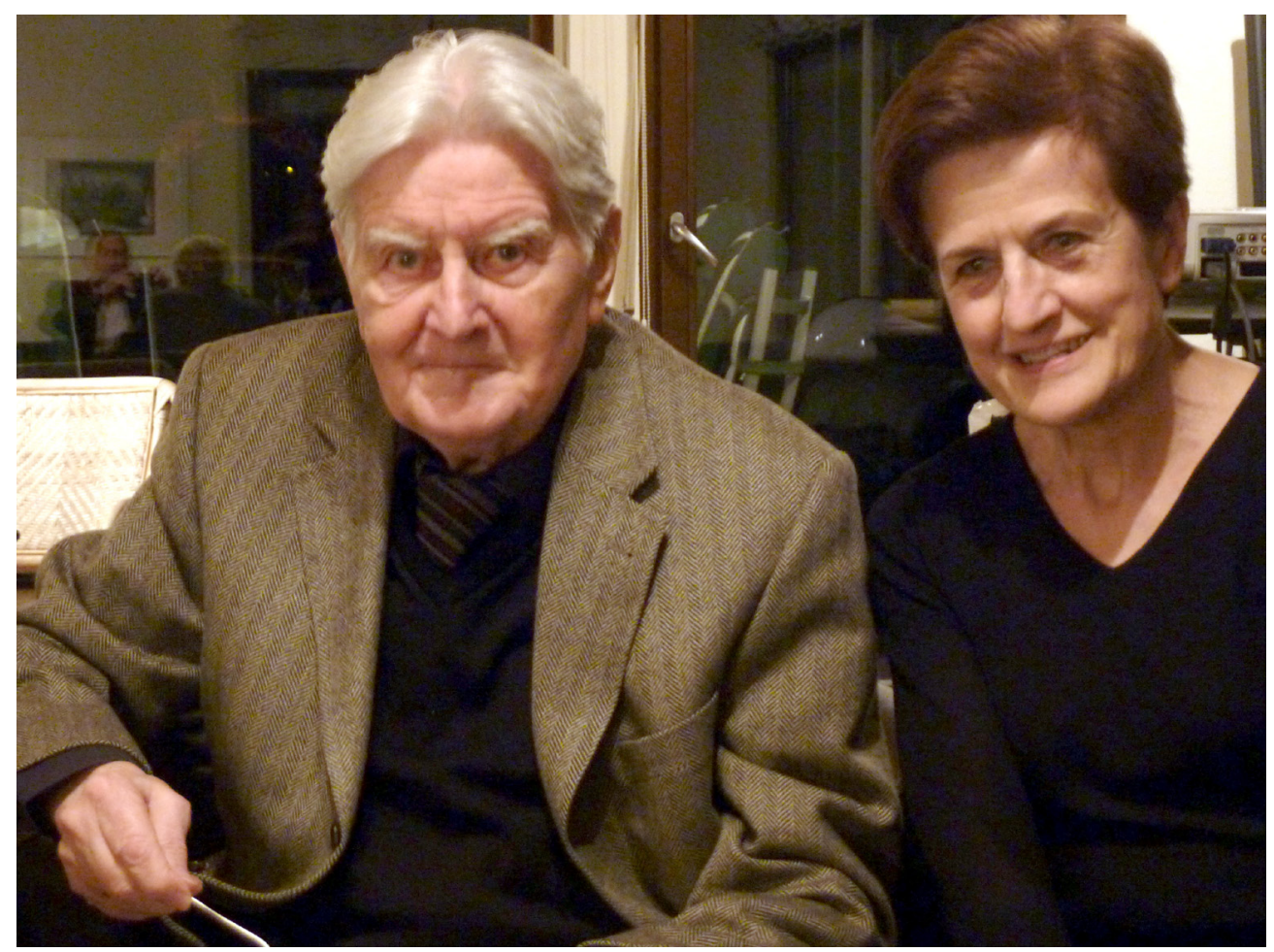

Karl Otto Apel y Adela Cortina en Niedernhausen (2012). 
